Research Paper

\title{
Poncirus Trifoliata (L.) Raf. Extract Inhibits the Development of Atopic Dermatitis-like Lesions in Human Keratinocytes and NC/Nga mice
}

\author{
Kyung-Jae Cha ${ }^{1 *}$, Ayesha Kashif ${ }^{*}$, Min Hwa Hong${ }^{1}$, Geunyeong Kim ${ }^{1}$, Ji-Sook Lee ${ }^{\circledR}$, In Sik Kim ${ }^{1,3}$ \\ 1. Department of Senior Healthcare, BK21 Plus Program, Graduate School, Eulji University, Daejeon 34824; \\ 2. Department of Clinical Laboratory Science, Wonkwang Health Science University, Iksan, 54538; \\ 3. Department of Biomedical Laboratory Science, School of Medicine, Eulji University, Daejeon 34824, Republic of Korea. \\ *These authors contributed equally to this work
}

$\triangle$ Corresponding author: Dr. In Sik Kim, Professor, Department of Biomedical Laboratory Science, School of Medicine, Eulji University, 77, Gyeryoung-ro 771 beon-gil, Jung-Gu, Daejeon, 34824, Republic of Korea. Tel: +82-42-259-1753 Fax: +82-42-259-1759 E-mail: orientree@eulji.ac.kr; Dr. Ji-Sook Lee, Associate Professor, Department of Clinical Laboratory Science, Wonkwang Health Science University, Iksandaero, Iksan, 54538, Republic of Korea. Tel: +82-63-840-1216 Fax: +82-63-840-1219 E-mail address: jslee1216@wu.ac.kr;

(c) The author(s). This is an open access article distributed under the terms of the Creative Commons Attribution License (https://creativecommons.org/licenses/by/4.0/). See http://ivyspring.com/terms for full terms and conditions.

Received: 2019.02.22; Accepted: 2019.06.21; Published: 2019.08.06

\begin{abstract}
This study investigated the anti-allergic effect of Poncirus trifoliata (L.) Raf. (PT) on human keratinocytic $\mathrm{HaCaT}$ cells in vitro and on 2,4-dinitrochlorobenzene (DNCB)-induced atopic dermatitis-like lesions in vivo. The release of TARC, MCP-1, IL-6 and IL-8 is increased by IFN-Y and TNF- $\alpha$ in $\mathrm{HaCaT}$ cells, and PT extract suppressed the increased production of TARC, MCP-1, IL-6, and IL-8. PT extract recovered the expression of filaggrin decreased by IFN- $\gamma$ and TNF- $\alpha$. in vivo experiment, PT administration decreased the skin severity score, thickening of the epidermis, movement of inflammatory cells into the dermis, and serum lgE level as compared to DNCB treatment. Moreover, the decrease of filaggrin and loricrin induced by DNCB treatment was recovered by PT administration. The levels of IL-4, IL-5, IL-13 and eotaxin in mouse splenocytes increased after treatment with concanavalin A, and the secretions of IL-4, IL-5, IL-13 and eotaxin were lower in the PT-treated group than in the DNCB group. These findings may indicate that PT is useful in drug development for the treatment of $A D$.
\end{abstract}

Key words: Atopic dermatitis, Poncirus trifoliata (L.) Raf., Anti-inflammatory effect, Filaggrin

\section{Introduction}

Atopic dermatitis (AD; eczema) is a type of hypersensitivity of the skin. AD primarily occurs in infant and children and is involved in excess immune responses to allergens, immune deviation, barrier dysfunction and genetic abnormality [1-3]. The level of serum immunoglobulin $\mathrm{E}$ (IgE) increases in patients with $\mathrm{AD}$ and includes antibodies to a variety of food and allergens $[4,5]$. AD is characterized by an increase in inflammatory cells and cytokines, and by a decrease in skin barrier proteins such as filaggrin [6-8]. Filaggrin is an important protein expressed in keratinocytes and is related to the maintenance of skin barrier role $[9,10]$. Impaired filaggrin can contribute to allergic sensitization, enhance inflammatory responses accompanied by erythema, itchiness, and scratching of the skin, and finally result in development and aggravation of AD.

Poncirus trifoliata (L.) Raf. (PT) is used as an herb in Korea for the treatment of gastrointestinal disorders [11]. It has also been reported in anti-oxidant, anti-bacterial, and anti-allergic activities [12-16].

In the present study, we examined the suppressive effect of PT on cytokine secretion and the expression of skin barrier proteins such as filaggrin, loricrin, and involucrin in vitro. In addition, we 
investigated the effect of $\mathrm{PT}$ on attenuation of $\mathrm{AD}$ development in AD-like NC/Nga mice in vivo.

\section{Materials and methods}

\section{Preparation of PT extract}

Whole PT plants (30g) were dried and incubated with DMSO for $24 \mathrm{~h}$ at room temperature. The complete PT extracts were used in this study. Voucher specimens No. 032-088) were stored at the herbaria of the Department of the Herbal Pharmaceutical Development, Korea Institute of Oriental Medicine, Daejeon, Korea.

\section{Cell culture}

HaCaT cells were cultured in Iscove's medium and DMEM supplemented with $10 \%$ heat-inactivated fetal bovine serum (FBS), penicillin $(100 \mathrm{U} / \mathrm{mL})$, and streptomycin $(100 \mu \mathrm{g} / \mathrm{mL})$ (Gibco-BRL, Grand Island, NY, USA). The cultured cells were maintained at $5 \%$ $\mathrm{CO}_{2}$ incubator. Cell viability was assayed based on the conversion of MTT by using a cell proliferation kit (Roche Korea, Seoul, Korea).

\section{Enzyme-linked immunosorbent assay}

After pretreatment with PT extract, HaCaT cells were treated with IFN- $\gamma$ and TNF- $\alpha$. Splenocytes were pretreated in the absence or presence of PT and then stimulated with $1 \mu \mathrm{g} / \mathrm{mL}$ concanavalin A (Sigma-Aldrich Korea, Seoul, Korea) for $24 \mathrm{~h}$ and $48 \mathrm{~h}$. Cell supernatants were collected and the concentrations of TARC, IL-6, IL-8, MCP-1, IL-4, IL-5, IL-13, and eotaxin were measured in the supernatant by sandwich ELISA (BD Biosciences, San Jose, CA, USA and R\&D Systems). The concentrations of alanine aminotransferase (ALT) and aspartate aminotransferase (AST) in the serum of NC/Nga mice were measured by ALT and AST assay kits (Asan Pharm, Seoul, Korea).

\section{Western blotting}

Following treatment with stimulatora, HaCaT cells were harvested and lysed in lysis buffer. Samples were separated by performing 10\% SDS-PAGE and then transferred to nitrocellulose membrane. Blots were incubated with antibodies against filaggrin, phospho-JNK (Santa Cruz Biotechnology, Santa Cruz, CA, USA), involucrin, or loricrin (Proteintech, Rosemont, IL, USA). After incubation, the membrane was developed by using an enhanced chemiluminescence detection system (Amersham Pharmacia Biotech, Piscataway, NJ, USA).

\section{Atopic dermatitis induction and PT treatment in $\mathbf{N C / N g a ~ m i c e ~}$}

Female 5-week-old NC/Nga mice ( $25 \pm 2$ g) (SLC
Japan, Shizuoka, Japan) were used in this experiment. They were housed in an air-conditioned animal experiment room with a room temperature and a $50 \pm$ $10 \%$ humidity. Before AD induction, the dorsal hair of NC/Nga mice was shaved off. There was not any sign of skin damage. $\mathrm{AD}$ was induced by stimulation with 2,4-dinitrochlorobenzene (DNCB, Sigma-Aldrich Korea). A $1 \%$ DNCB solution $(0.15 \mathrm{~mL})$ dissolved in an acetone-olive oil mixture (acetone:olive oil = 3:1) was applied to the shaved dorsal skin area. After this initial sensitization treatment, the mice were dorsally treated with $0.3 \% \mathrm{DNCB}$ at 1 week intervals for 5 weeks. The NC/Nga mice were classified into four groups; untreated, control, PT, and dexamethasone (DEX) groups. The control, PT, and DEX groups were dorsally treated with $1 \%$ DNCB and thereafter were dorsally administered with $0.3 \%$ DNCB for 12 weeks. The control, PT, and DEX groups had phosphate-buffered saline (PBS), PT extract (100, 200, $500 \mu \mathrm{g} / \mathrm{kg})$, and DEX $(5 \mathrm{mg} / \mathrm{kg})$, respectively, applied to the same area of dorsal skin for 7 weeks after sensitization with $0.3 \%$ DNCB. The untreated group was treated with PBS. The severity of dermatitis was assessed macroscopically in a blinded fashion according to our previous paper [6]. Experimental procedures were approved by the Institutional animal care and use committee, Eulji University (Approval number: EUIACUC- 15-10).

\section{Histological analysis}

After sacrificing the mice, the dorsal skin was separated and fixed in Carnoy's solution, embedded in paraffin (Sigma-Aldrich Korea) and sectioned. The tissue sections were then stained with hematoxylin-eosin solution or alcian blue (Sigma-Aldrich Korea). Finally, the sections were examined by using light microscopy (Leica Microsystems, Wetzlar, Germany) for histological evaluation. For immunohistochemical staining, we performed on $4 \mu \mathrm{m}$-thick paraffin sections with a automated tissue staining system of Ventana Medical Systems Inc. (TuPTon, AZ, USA). The sections were placed on SuperfrostPlus microscope slides (Fisher Scientific, Madison, WI, USA). An OptiView DAIHC Detection Kit (Ventana Medical Systems) was used as a 3,3'-diaminobenzidine (DAB) for detecting antibodies. Sections were deparaffinized with EZ Prep solution. CC1 standard (Tris/Borate/EDTA, pH 8.4) was used for antigen retrieval. Slides were incubated with anti-filaggrin, anti-involucrin or anti-loricrin antibody (Santa Cruz Biotechnology) after which they were incubated with OptiView HRP Multimer, $\mathrm{HQ}$ Universal Linker, and $\mathrm{H}_{2} \mathrm{O}_{2}$. After incubating with OptiView DAB and copper, they were counterstained and post-counterstained with 
hematoxylin-eosin and bluing reagent, respectively.

\section{Measurement of serum IgE}

Blood was collected from the retro-orbital plexus of the mice on the day of euthanizing. Serum was obtained by centrifugation and stored at $-70^{\circ} \mathrm{C}$ until required. Total IgE levels in the serum were measured by using a sandwich ELISA kit (R\&D Systems, Minneapolis, MN, USA).

\section{Splenocyte preparation}

Mice were euthanized, and subsequently, their A

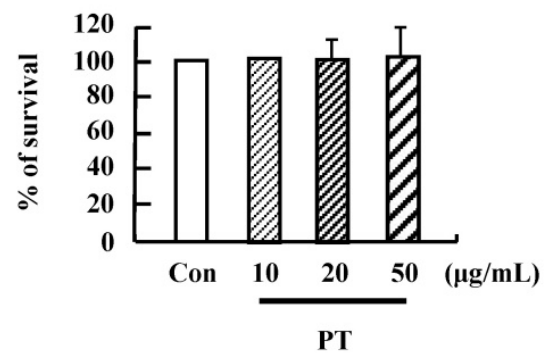

B
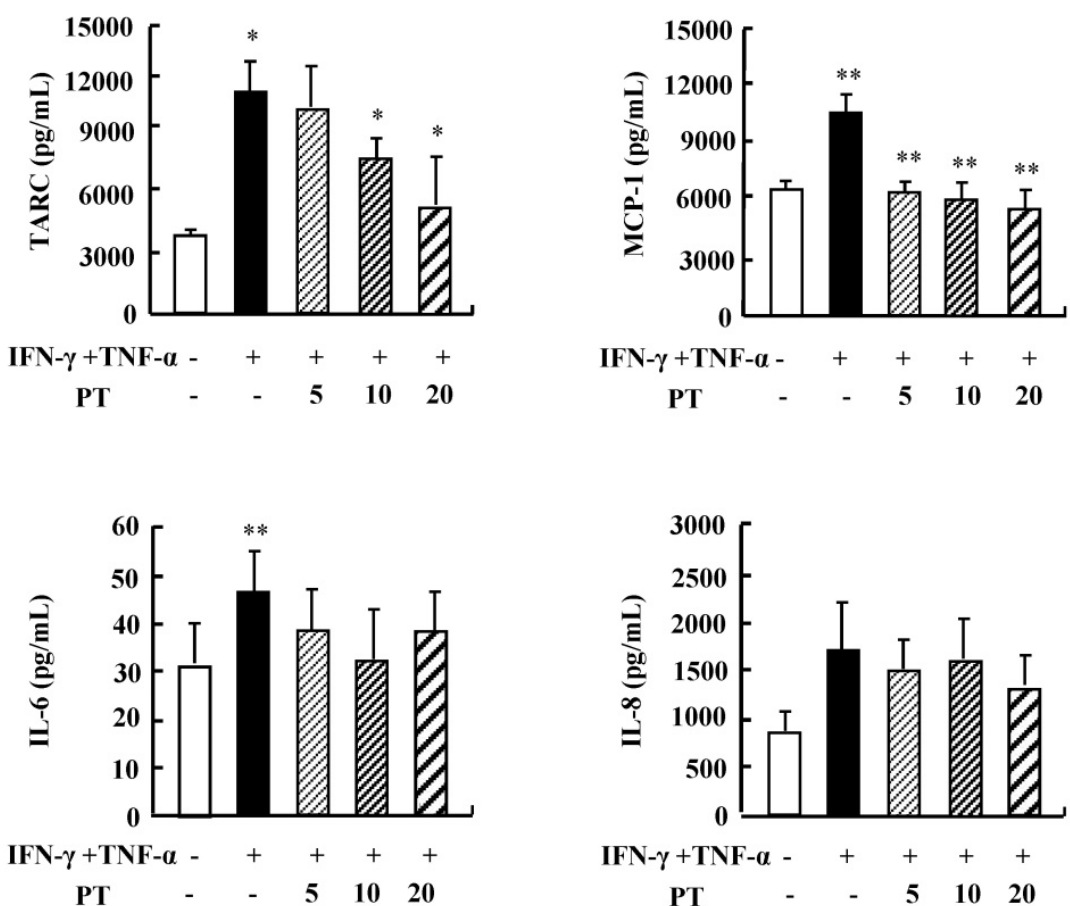

Figure 1. PT inhibits the cytokine release of $\mathrm{HaCaT}$ cells. (A) $\mathrm{HaCaT}$ cells were incubated in the absence (medium alone) or presence of PT extract at the indicated concentrations for $48 \mathrm{~h}$. Survival rate was measured by performing MTT-based viability assay. Data are presented as a mean \pm SD of three independent experiments and expressed as a relative ratio to the absorbance of untreated cells, which was set at $100 \%$ d. (B) $\mathrm{HaCaT}$ cells were pretreated in the absence or presence of PT extract at the indicated concentrations. Cells were treated with $10 \mathrm{ng} / \mathrm{mL}$ IFN- $\gamma$ and TNF- $\alpha$ for $24 \mathrm{~h}$. The supernatant was collected and analyzed by using ELISA. Data are presented as the mean \pm SD of three independent experiments with statistical significance as $* \mathrm{P}<0.05$ and $* * \mathrm{P}<0.01$ between untreated and IFN- $\gamma$ and TNF- $\alpha$-treated groups or between the IFN- $\gamma$ and TNF- $\alpha$-treated group and the PT-treated group. spleens were removed under aseptic conditions. Splenocytes were then isolated from the spleens after which the red blood cells were hemolyzed by using a red blood cell lysis solution (Sigma-Aldrich). Splenocytes were seeded in a 24-well plate at a density of $5 \times 10^{6}$ cells $/ \mathrm{mL}$ in RPMI-1640 medium supplemented with $1 \%$ penicillin-streptomycin and $10 \%$ FBS.

\section{Statistical analysis}

Data are represented as a mean \pm standard deviation (SD). Intergroup differences were evaluated by the Student's t-test within SPSS software (SPSS, Chicago, IL, USA). $P<$ 0.05 was considered as a statistically significant difference.

\section{Results}

\section{PT inhibits the cytokine release of HaCaT cells}

We examined the optimal treatment concentration of PT extract in HaCaT cells. PT extract was not effective on survival rate of HaCaT cells after stimulation with PT extract at concentrations ranging from $10 \mathrm{ug} / \mathrm{mL}$ to $50 \mathrm{ug} / \mathrm{mL}$ for $48 \mathrm{~h}$ (Fig. 1A). Treatment with IFN- $\gamma$ and TNF- $\alpha$ increased the secretion of TARC, MCP-1, IL-6 and IL-8 (Fig.1B). PT decreased the production of TARC, MCP-1, and IL-8 induced by IFN- $\gamma$ and TNF- $\alpha$ stimulation. These results indicate that PT extract suppresses the secretion of inflammatory cytokines in $\mathrm{HaCaT}$ cells during an inflammatory response. 


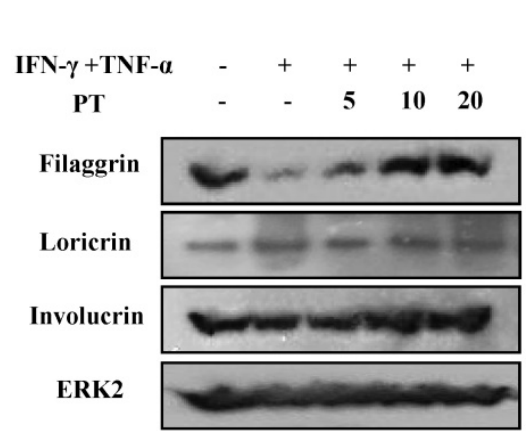

Figure 2. PT recovers the decrease of filaggrin induced by IFN-y and TNF- $\alpha$. HaCaT cells were preincubated in the absence and presence of PT at the indicated concentrations for $1 \mathrm{~h}$. The cells were then incubated with $10 \mathrm{ng} / \mathrm{mL}$ IFN- $\mathrm{y}$ and TNF- $\alpha$ for $48 \mathrm{~h}$. The harvested cells were lysed, and filaggrin, loricrin and involucrin were analyzed by western blotting. Densitometric data are expressed as a mean \pm SD and are presented relative to the negative control, which was set at 1 (right panel) with statistical significance as $* \mathrm{P}<0.05$ and $* * \mathrm{P}<0.01$ between the untreated and IFN- $\gamma$ and TNF- $\alpha$-treated group or between the IFN- $\gamma$ and TNF- $\alpha$-treated group and the PT-treated group.

\section{PT extract reduces the decrease of filaggrin induced by IFN-Y and TNF- $\alpha$}

We next investigated whether PT extract alters the expressions of filaggrin, loricrin, and involucrin. IFN-Y and TNF- $\mathrm{a}$ suppressed the expression of filaggrin. The decreased expression was recovered by PT extract in a dose-dependent manner (Fig. 2). The expressions of loricrin and involucrin were increased or was not altered by IFN- $\gamma$ and TNF- $a$, and PT extract increased the expressions of loricrin and involucrin. These results indicate that PT extract increases the expression of filaggrin under inflammatory processes that may result in a filaggrin decrease.

\section{PT extract decreases the aggravation of atopic-like skin lesion, histopathological features, and serum IgE in AD-induced mice}

For evaluating the suppressive effect of PT in the pathogenesis of $\mathrm{AD}$, we performed the clinical, histological, and serological analyses. NC/Nga mice were administered with DNCB for 5 weeks and thereafter PT extract was treated to the mice for 7 weeks. PT administration recovered the increase of a skin symptom severity score due to DNCB as compared to the control group, and the score of the PT-treated group was comparable to that of the DEX-treated group (Fig. 3A). The body weight of the PT-treated group was similar to that of the control group (Fig. 3B). Histological evaluation displayed hypertrophy, hyperkeratosis of the epidermis and infiltration of inflammatory cells in the control group (Fig. 3C). However, administration of PT extract relieved the histopathological alteration in a fashion comparable to the dexamethasone group. The level of serum IgE was higher in the control group than in the untreated group, while PT treatment blocked the increased IgE concentration in serum (Fig. 3D).
Moreover, the serum AST and ALT in the PT-treated group were similar to those in the untreated group (Fig. 3E).

\section{PT extract enhances the expression of filaggrin in AD-induced mice}

To evaluate the effect of PT extract on filaggrin in AD-induced mice, we performed both immunohistochemical staining and western blotting. Filaggrin expression in epidermis was more intense in the PT-treated group than in the control group (Fig. 4A). In experiments using western blotting, the expressions of filaggrin, loricrin, and involucrin decreased after DNCB administration, and they were recovered in the PT-treated group (Fig. 4B).

\section{PT extract inhibits the secretion of IL-4, IL-5, IL-13, and eotaxin in mouse splenocytes}

To investigate the anti-inflammatory effect of PT in DNCB-induced mice, splenocytes were isolated from mouse spleen at 12 weeks after the first DNCB sensitization. After the stimulation with concanavalin A for $24 \mathrm{~h}$ and $48 \mathrm{~h}$, the release of cytokines such as IL-4, IL-5, IL-13, and eotaxin increased in splenocytes of the control group, but the increased cytokines was diminished in splenocytes of the PT-treated group (Fig. 5). These results indicate that PT treatment affects the synthesis of cytokines and chemokines in the clinical state of AD.

\section{Discussion}

PT has been known to reveal anti-allergic effect including inhibition of IgE production, histamine release, and IL-5 synthesis [12-14, 17]. On that basis, this study was designed to examine the anti-inflammatory effect of PT on the pathogenesis of $\mathrm{AD}$ and the possibility of using PT extract in a therapeutic drug for the treatment of AD. 
In the development and aggravation of $\mathrm{AD}$, the regulation of cytokine secretion, particularly the Th1/Th2 cytokines and chemokines, is a key process [18). TARC, MCP-1, and IL-8 have been reported as survival factors and pathogenic inducers of AD [19]. IL-6 is secreted from T lymphocytes, macrophages, and eosinophils, and it plays an essential role in the transition from an acute inflammatory state to a chronic inflammatory state [20]. As shown in Fig. 1, PT extract decreased the expression of cytokines such as TARC, MCP-1, and IL-8 induced by IFN- $\gamma$ and TNF-a in human keratinocytic HaCaT cells. In AD-like NC/Nga mice, the PT-treated group, after st with concanavalin A for $24 \mathrm{~h}$ and $48 \mathrm{~h}$, represented lower production of Th2 cytokines such as IL-4, IL-5, and IL-13, and a chemokine, eotaxin, than the production levels in the control group (Fig. 5). Because IL-4, IL-5, and IL-13 is related to in increased IgE production in AD patients, PT may lower serum IgE level by suppressing the synthesis of Th2 cytokine (Fig. 3D) [21]. PT also may inhibit histopathological features by lowering the level of eotaxin attracting eosinophils (Fig. 3). PT includes more than 50 phytochemicals such as poncirin, limonene, synephrine, hesperidin, neohesperidin, auraptene and imperatorin [11]. 21-Methylmelianodiols are effective on inhibition of IL-5 production [17]. Hesperidin ameliorates UV radiation-induced skin damage and Auraptene suppresses IL-4 production [22, 23]. The alteration of cytokine expression in our results may be caused by these anti-inflammatory chemicals contained in PT extract.
A

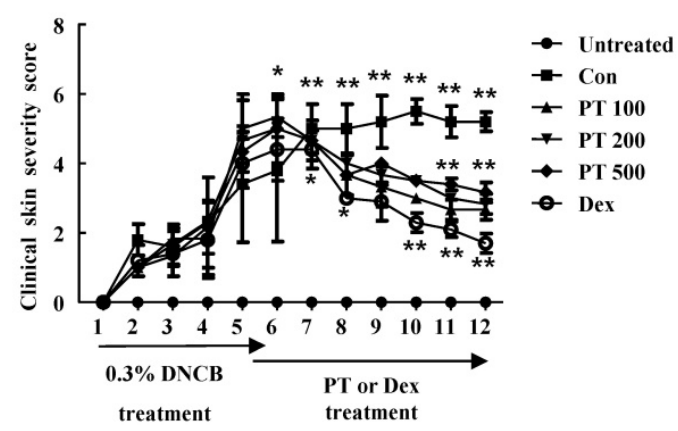

B

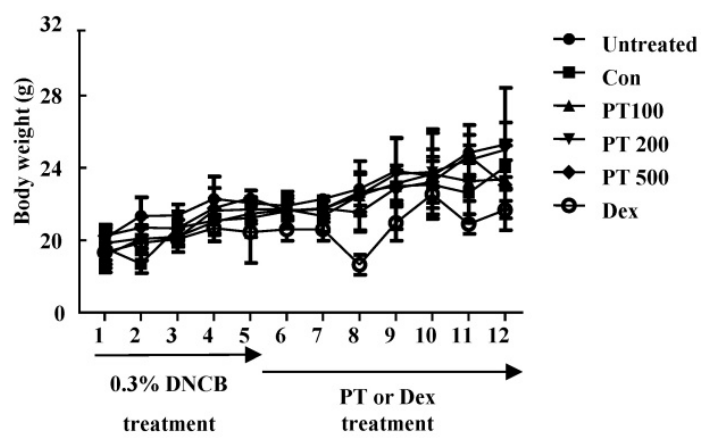

C

DNCB

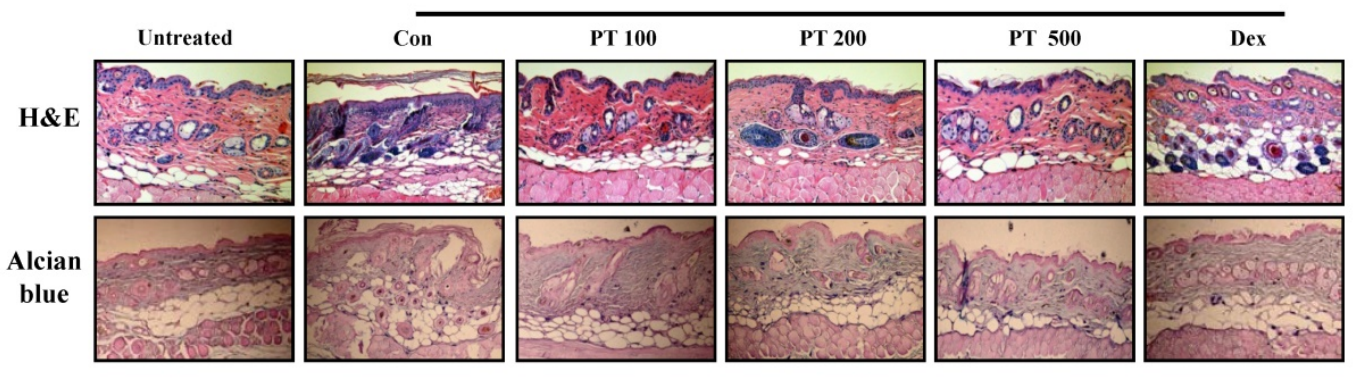

D

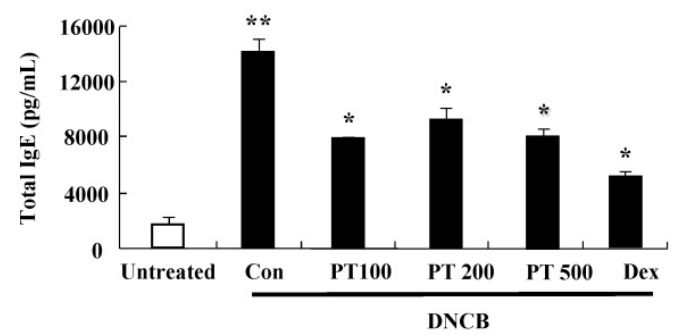

Figure 3. PT extract decreases the aggravation of atopic-like skin lesion, histopathological features, and serum IgE in DNCB-induced AD mice. The mice were divided into four groups: Untreated, control (Con), PT, and DEX. The control, PT, and DEX groups were dorsally administered with $1 \%$ DNCB and then dorsally treated with $0.3 \%$ DNCB. PT was administered orally at concentrations of 100,200 , and $500 \mu \mathrm{g} / \mathrm{kg}$. DEX was administered orally at $5 \mathrm{mg} / \mathrm{kg}$. (A) The severity of dermatitis was evaluted macroscopically in a blinded experiment. (B) Mouse mean body weight was measured by using an electric scale. Data are presented as a mean \pm SD. (C) For histological analysis, the dorsal skin was fixed, embedded in paraffin, sectioned, stained with hematoxylin-eosin and alcian blue, and examined by using light microscopy (magnification, $\times 100$ ). (D) Total serum IgE levels were measured by using sandwich ELISA kits. (E) The levels of AST and ALT were measured in the serum of NC/Nga mice by using the Reitman-Frankel method and ALT and AST assay kits. Data are presented as a mean \pm SD with statistical significance as $* P<0.05$ and $* * P<0.01$ between the untreated and control groups or between the control and PT-treated groups. 
A

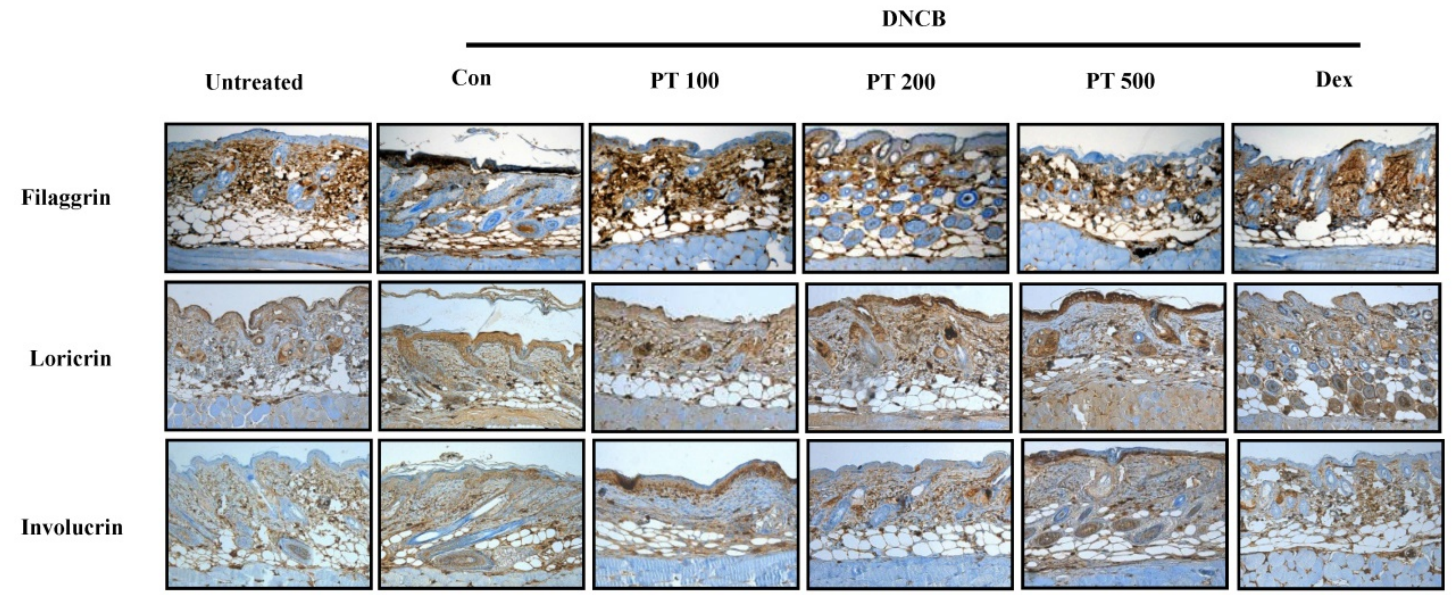

B

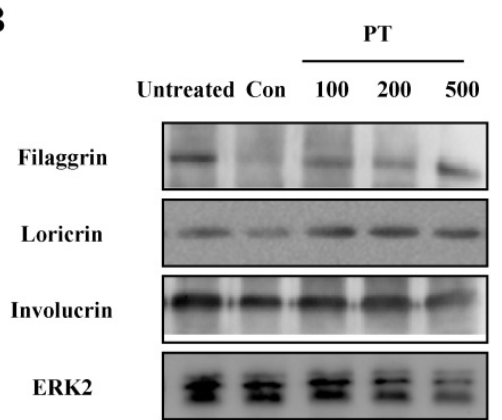

Filaggrin $\square$ Loricrin $\square$ Involucrin
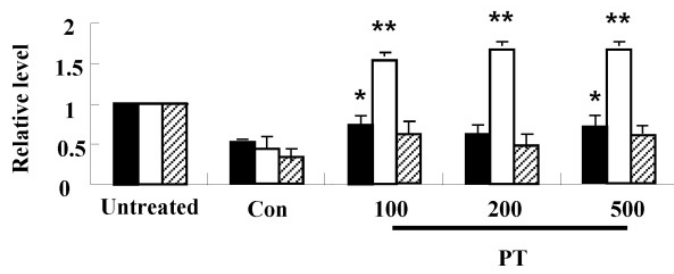

Figure 4. PT extract enhances the expression of filaggrin in skin of NC/Nga mice. (A) For filaggrin analysis, skin sections were fixed, embedded in paraffin, and stained with immunohistochemical stains. The samples were examined by using light microscopy (magnification, $\times 100$ ). (B) Filaggrin, loricrin, and involucrin as well as phospho-JNK, in the dorsal skin were analyzed by western blotting. Densitometric data are expressed as means \pm SD and are presented relative to the negative control, which was set at 1 (right panels of $\mathrm{B}$ ). $* P<0.05$ and $* * P<0.01$ indicate a statistical significance between the untreated and control groups or between the control and PT-treated groups.
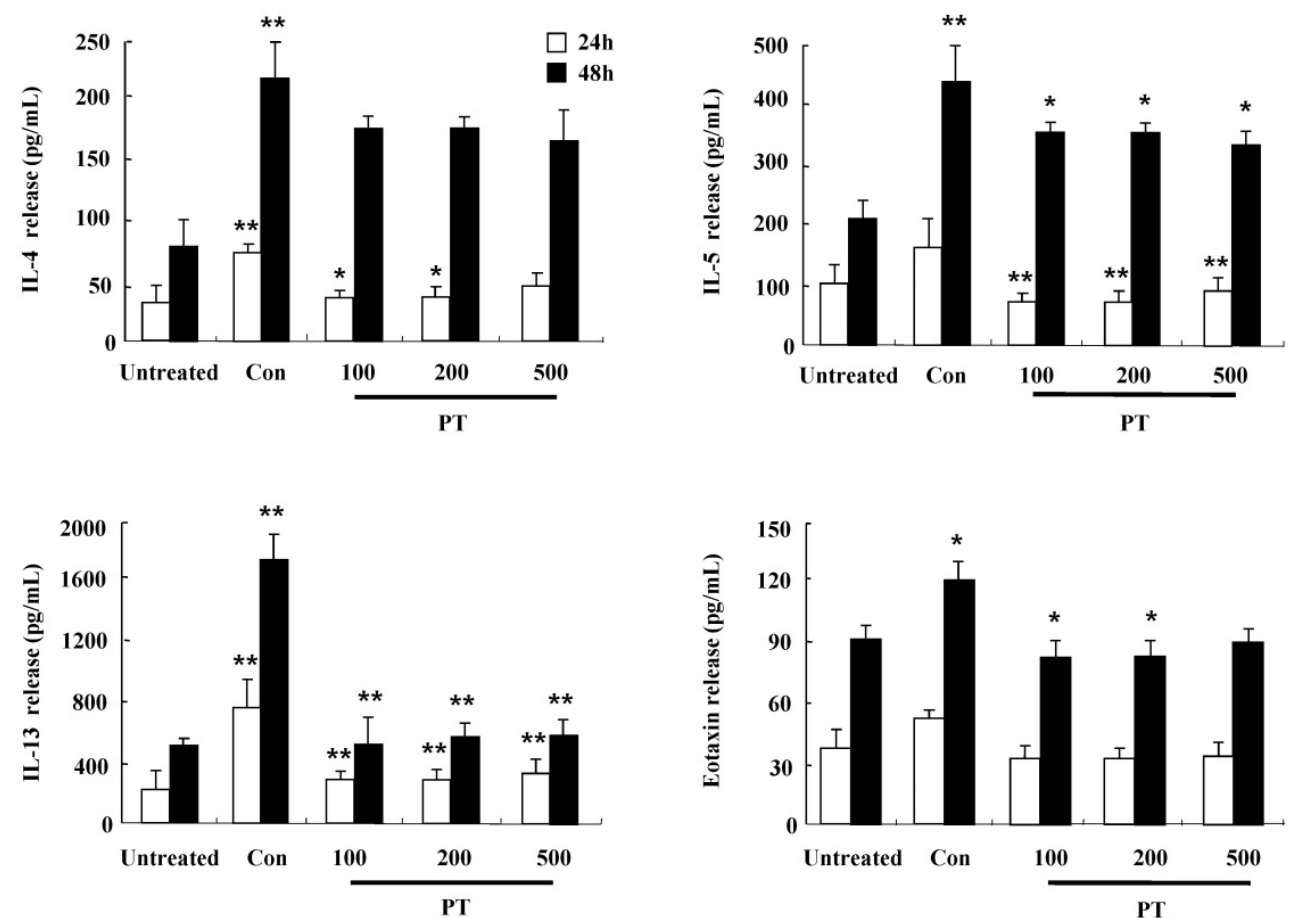

Figure 5. PT extract inhibits the secretion of IL-4, IL-5, IL-13, and eotaxin in mouse splenocytes. Splenocytes were isolated from NC/Nga mice of the untreated, control (Con), and PT groups. Subsequently, the cells were treated with $1 \mu \mathrm{g} / \mathrm{mL}$ concanavalin A for $24 \mathrm{~h}$ and $48 \mathrm{~h}$. Supernatants were collected and analyzed by ELISA. Data are presented as means \pm SD with statistical significance as $* P<0.05$ and $* * P<0.01$ between the untreated and control groups or between the control and PT-treated groups. 
Defects in skin barrier proteins are important for the development of AD. IFN- $\gamma$ and TNF- $\alpha$ activate the mitogen-activated protein kinase-mediated mechanism, which regulates the expression of filaggrin [19, 24, 25]. Our results demonstrate that IFN- $\gamma$ and TNF- $\alpha$ suppressed filaggrin expression in $\mathrm{HaCaT}$ cells and PT increased filaggrin expression during $\mathrm{AD}$ state (Figs. 2 and 4). Loricrin and involucrin also are essential skin barrier proteins. PT enhanced the expressions of loricrin and involucrin, which have been decreased by DNCB treatment (Fig. 4). IL-4 decreases CBP binding to the involucrin transcription complex, which results in downregulation of involucrin expression [26]. IL-13 plays an important role in downregulation of filaggrin, loricrin, and involucrin through STAT pathway [27]. Increase of IL-4 and IL-13 in AD may be deeply implicated in downregulation of skin barrier proteins (Fig. 5). Further study is required to examine concise signal pathways activated by PT.

In AD-like NC/Nga mice, the DNCB-treated control group displayed increased clinical skin severity score, serum IgE level, and histopathological skin lesions (Figs. 4 and 5). The PT-treated group displayed a low skin symptom severity score, alleviation of histopathological features such as infiltration of inflammatory cells and epidermis hypertrophy, and a low serum IgE compared to those in the control group. These results are comparable to the effects of other herb extracts reported in other papers $[7,28]$.

In conclusion, we demonstrated that PT extract suppresses inflammatory cytokines and chemokines and that it alleviated the skin inflammation and defect of skin barrier proteins in AD-like NC/Nga mice. This work gives a new insight on the development of a therapeutic drug for the treatment of AD.

\section{Abbreviations}

Dexamethasone: DEX; DNCB: 2,4dinitrochlorobenzene; PT: Poncirus Trifoliata (L.) Raf.

\section{Acknowledgements}

This work was supported by the BK21 plus program through the National Research Foundation(NRF) funded by the Ministry of Education of Korea.

\section{Competing Interests}

The authors have declared that no competing interest exists.

\section{References}

1. De Benedetto A, Agnihothri R, McGirt LY, et al. Atopic dermatitis: a disease caused by innate immune defects? J Invest Dermatol. 2009; 129: 14-30.
2. Barnes KC. An update on the genetics of atopic dermatitis: scratching the surface in 2009. J Allergy Clin Immunol. 2010; 125: 16-29.

3. Cho BO, Che DN, Yin $\mathrm{HH}$, et al. Diospyros lotus leaf and grapefruit stem extract synergistically ameliorate atopic dermatitis-like skin lesion in mice by suppressing infiltration of mast cells in skin lesions. Biomed. Pharmacother. 2017; 89: 819-26.

4. Gould HJ, Sutton BJ. IgE in allergy and asthma today. Nat Rev Immunol. 2008; 8: 205-17.

5. Chen Y, Xian Y, Lai Z, et al. Anti-inflammatory and anti-allergic effects and underlying mechanisms of Huang-Lian-Jie-Du extract. Implication for atopic dermatitis treatment. J Ethnopharmacol. 2016; 185: 41-52.

6. Kim IS, Kim DH, Yun CY, et al. A (S)-(+)-decursin derivative, (S)-(+)-3-(3,4-dihydroxy-phenyl)-acrylic acid 2,2-dimethyl-8-oxo-3,4-dihydro-2H,8H-pyrano [3,2-g]-chromen-3-yl-ester, attenuates the development of atopic dermatitis-like lesions in NC/Nga mice. Mol Biol Rep. 2013; 40: 2541-48.

7. Sung YY, Lee AY, Kim HK. Forsythia suspensa fruit extracts and the constituent matairesinol confer anti-allergic effects in an allergic dermatitis mouse model. J Ethnopharmacol. 2016; 187: 49-56.

8. He Y, Sultana I, Takeda K, et al. Cutaneous deficiency of filaggrin and STAT3 exacerbates vaccinia disease in vivo. PLoS One. 2017; 12:e170070.

9. Cabanillas B, Novak N. Atopic dermatitis and filaggrin. Curr Opin Immunol . 2016; 42: 1-8.

10. Tenn MW, Ellis AK. The clinical relevance of filaggrin mutations: Effect on allergic disease. Ann. Allergy Asthma Immunol. 2016; 117: 483-9.

11. Choi KH, Jeong SI, Hwang BS, et al. Hexane extract of Poncirus trifoliata (L.) Raf. stimulates the motility of rat distal colon. J Ethnopharmacol. 2010; 127: 718-24.

12. Lee YM, Kim DK, Kim SH, et al. Antianaphylactic activity of Poncirus trifoliata fruit extract. J Ethnopharmacol. 1996; 54: 77-84.

13. Lee YM, Kim YC, Kim HM. Effects of Poncirus trifoliata on type I hypersensitivity reaction. Am. J. Chin. Med. 1997; 25: 51-6.

14. Kim DH, Bae EA, Han MJ. Anti-helicobacter pylori activity of the metabolites of poncirin from Poncirus trifoliata by human intestinal bacteria. Biol Pharma Bul. 1999; 22: $422-24$.

15. Kim HM, Kim HJ, Park ST. Inhibition of immunoglobulin E production by Poncirus trifoliata fruit extract. J Ethnopharmacol. 1999; 66: 283-88.

16. Jayaprakasha GK, Mandadi KK, Poulose SM, et al. Inhibition of colon cancer cell growth and antioxidant activity of bioactive compounds from Poncirus trifoliata (L.) Raf. Bioorg Med Chem. 2007; 15: 4923-32.

17. Lee IJ, $\mathrm{Xu} \mathrm{GH}, \mathrm{Ju} \mathrm{JH}$, et al. 21-Methylmelianodiols from Poncirus trifoliata as inhibitors of interleukin-5 bioactivity in Pro-B cells. Planta Med. 2008; 74: 396-400.

18. Suto H, Matsuda H, Mitsuishi K, et al. NC/Nga mice: a mouse model for atopic dermatitis. Int Arch Allergy Immunol. 1999. 120: 70-5.

19. Cha KJ, Im MA, Gu A, et al. Inhibitory effect of Patrinia scabiosifolia Link on the development of atopic dermatitis-like lesions in human keratinocytes and NC/Nga mice. J Ethnopharmacol. 2017; 206: 135-43.

20. Hirano T. Interleukin 6 and its receptor: ten years later. Int Rev Immunol. 1998; 16: 249-84.

21. Bieber T. Atopic dermatitis. Ann Dermatol. 2010; 22: 125-37.

22. Niu X, Huang Z, Zhang L, et al. Auraptene has the inhibitory property on murine T lymphocyte activation. Eur J Pharmacol. 2015; 750: 8-13.

23. Lee J, Choi YY, Kim MH, et al. Topical application of Angelica sinensis improves pruritus and skin inflammation in mice with atopic dermatitis-like symptoms. J Med Food. 2016; 19: 98-105.

24. Chang L, Karin M. Mammalian MAP Kinase signaling cascades. Nature. 2001; 410: 33-40.

25. Lin A. Activation of the JNK signaling pathway: breaking the brake on apoptosis. Bioessays. 2003; 25:17-24.

26. Bao L, Alexander JB, Zhang $\mathrm{H}$, et al. Interleukin-4 Downregulation of Involucrin Expression in Human Epidermal Keratinocytes Involves Stat6 Sequestration of the Coactivator CREB-Binding Protein. J Interferon Cytokine Res. 2016; 36: 374-81.

27. Zeng YP, Nguyen GH, Jin HZ, et al. MicroRNA-143 inhibits IL-13-induced dysregulation of the epidermal barrier-related proteins in skin keratinocytes via targeting to IL-13Ra1. Mol Cell Biochem. 2016; 416: 63-70.

28. Kwak MH, Kim JE, Hwang IS, et al. Quantitative evaluation of therapeutic effect of Liriope platyphylla on phthalic anhydride-induced atopic dermatitis in IL-4/Luc/CNS-1 Tg mice. J Ethnopharmacol. 2013; 148: 880-89. 